\title{
Correction to: Gender differences in SCRABBLE performance and associated engagement in purposeful practice activities
}

\author{
Jerad H. Moxley ${ }^{1,3}\left[\right.$ K. Anders Ericsson ${ }^{2} \cdot$ Michael Tuffiash $^{2}$
}

Published online: 21 September 2018

๑) Springer-Verlag GmbH Germany, part of Springer Nature 2018

\section{Correction to: Psychological Research https://doi.org/10.1007/s00426-017-0905-3}

In the original publication of this article there is a mistake in the Results of Study 2a involving the CFA and the SEM. The corrected Tables and figures are given below.

Table 3. Table 3 has a typo. The value for the "All" column associated with Log play self of $3.80(0.48)$ should be 0.97 (1.54).

CFA and SEM without covariates. Table 4, Table 5, and Fig. 1 present results in part based on a CFA/SEM with 4 latent variables and with 1 observed variable, tournament play, treated as a separate observed factor. This model has an extremely high correlation between play and general word study of $r=0.995$, which indicates the factors are empirically redundant. A colleague pointed out that our output reported a non-positive definite matrix, indicating that valid inferences cannot be derived from that model. We should have noted this high correlation and combined the two factors in the analysis. The Other SCRABBLE Activity factor would have given rise to these observed variables as indicators: play against computer, play against others, create word list, study word spellings (incorrectly labeled "study word list" in Fig. 1), and study definitions. This appropriately revised model supports our previous analysis and shows a better model-fit than any previously reported in our paper, $\chi^{2}(39)=43.14, p=0.30, \chi^{2} / d f=1.11, \mathrm{SRMR}=0.057$, $\mathrm{TLI}=0.96, \mathrm{CFI}=0.97, \mathrm{RMSEA}=0.02990 \%$ CI $[0.00$,

The original article has been corrected.

Jerad H. Moxley

jhm2006@med.cornell.edu

1 University of Miami Miller School of Medicine, Miami, USA

2 Florida State University, Tallahassee, USA

3 Center for Aging, Jackson Behavioral Health, 1695 NW 9th Ave, Miami, FL 33136, USA
0.07]. The decrease in fit from a five factor model with general word study and play separated is not statistically significant, $\Delta \chi^{2}(4)=4.81, p=0.31$. Figure E1 shows this model.

CFA and SEM with age and gender covariates. The model predicting SCRABBLE rating that paralleled the model reported in the previous paragraph, while including age and gender covariates, was still non-positive definite, where valid inferences also cannot be derived from the model. This was due to high correlations (collinearity) between the set of age variables and the latent variables. This may be interesting in and of itself because, with the possible exception of the effect of increased age, we would not have expected these variables to explain any variance past properly measured practice variables, (though see Gobet and Campitelli 2007, referenced in paper for an argument on why starting age might predict performance independently of practice).

An SEM with the three latent variables-tournament play, gender, and rating - does converge with gender set as a predictor of the three latent variables as well as tournament play, and all variables including gender predicting rating, $\chi^{2}(53)=78.93, p=0.01, \chi^{2} / d f=1.49, \mathrm{SRMR}=0.065$, $\mathrm{TLI}=0.83, \mathrm{CFI}=0.88, \mathrm{RMSEA}=0.06390 \%$ CI $[0.03$, $0.09]$. In this model, gender predicted SCRABBLE specific practice alone, $b$ (always standardized in this analysis) $=-0.32, p=0.001$, but importantly, gender did not predict anything else. Rating was predicted positively by SCRABBLE-specific practice alone $(b=0.59, p=0.002)$, negatively by Other SCRABBLE $(b=-0.36, p=0.03)$, and positively by tournament play $(b=0.24, p=0.008)$. Gender was non-significant $(b=-0.02, p=0.87)$. The total indirect effect of gender was $b=-0.31, p<0.01$ with only SCRABBLE specific practice alone significantly mediating the effect of gender on rating, $b=-0.19, p=0.03$. This model accounted for $40 \%$ of the variance in SCRABBLE rating. This was likely the most appropriate analysis. This model is presented in Fig. E2. 
Table 6. Table 6 reflects the final mediational model based five factors. Combining other SCRABBLE play and general word study should be replicated in future studies, as we can argue for or against the logic of this pairing, as well as for the analysis of alternative models. Because a multiple regression model can fit the data, that analysis serves in some ways to show a slightly different model that better fits our initial intuition. For completeness sake, we report the analysis in Table E2 as it would be, given the revised analysis presented in this document.

As with the original analysis, the results replicate Study 1. Gender had a positive indirect effect on rating through age $b$ (always unstandardized in this analysis) $=68.35,95 \% \mathrm{CI}$ $[18.02,157.95]$. Gender showed a negative indirect effect on rating through first tournament experience, $b=-87.79$, 95\% CI [-174.46, - 31.75] as well as through SCRABBLE specific practice alone, $b=-24.52,95 \%$ CI $[-66.17$, -3.62]. No other variable reliably mediated the effect of gender on rating. The overall lack of a gender difference in SCRABBLE activity $F(1,120)=0.64, p=0.43$, with females reporting an insignificantly larger amount, is unchanged by these analysis.

Five-factor model description. In the last paragraph of the discussion of Study 2a, we mention the five factor model incorrectly:

"While the factor analysis identified five different independent factors to describe the shared variance in engagement in many SCRABBLE-related activities, only two of these factors were statistically significantly related directly to SCRABBLE skill in our Study 2A model. These were the two types of practice identified in Study 1, with general vocabulary study (an activity that is done alone) being negatively related to skill and
SCRABBLE-specific practice alone being positively related to skill" (p. 12).

Two of the factors were not independent, and so this statement is incorrect as stated and should instead reflect four different independent factors.

Conclusion. The main substantive conclusion of the SEM analysis in the original draft, is that with better measurement, SCRABBLE specific practice alone explains the statistically significant covariance between gender and rating observed in these data; and this appears to hold in the revised analysis. Additionally, SCRABBLE practice outside of SCRABBLE-specific practice alone and tournament play negatively predicted performance. The main difference is tournament experience positively predicted rating in this model and was not in the SEM originally presented in Table 5. It should be noted tournament experience did predict rating in the mediation model presented in Table 6 (and again in Table E2). We emphasize, as we did in the original draft, that although the gender coefficient is even smaller in this analysis when compared to what was discussed in the main paper, our sample is not large enough to conclude definitively that there is no practically significant gender difference in SCRABBLE skill. Additionally, there are likely factors not measured in this study that alter the effect of gender. We also note again that future studies need to replicate the factor structure found here in comparison with other reasonable factor structures.

We are extremely grateful to Fred Oswald for pointing out the issue and discussing with the first author how it might be addressed. We thank Fred Oswald, Zach Hambrick and Brooke Macnamara for comments on earlier drafts. 




Figure E1. Correcting Fig. 1 CFA results. Ana study anagrams, angame analysis games of others, anown analyze own games, com play SCRAABBLE against computer, createwl create world list, def study definitions, others play SCRABBLE against other people, self play SCRABBLE against self, studyword study word spellings, tourney play in a SCRABBLE tournament, wordg play word games other than SCRABBLE



Figure E2. Correcting Table 5. SEM results for four factors without the variables of age, starting age, and first tournament age. Statistically significant paths and values are black, and non-significant paths and values are gray 


\section{Table E1 Correcting Table 4}

Goodness-of-fit indicators of models for practice activities in scrabble and the structural equation model (SEM) for relation between practice and demographic variables with SCRABBLE skill $(N=122)$

\begin{tabular}{llllllll}
\hline Model & $d f$ & $\chi^{2}$ & $\chi^{2} / d f$ & SRMR & TLI & CFI & RMSEA \\
\hline Single factor & 44 & $83.70^{* *}$ & 1.90 & 0.086 & 0.67 & 0.74 & 0.086 \\
Two factors & 42 & $81.21^{* *}$ & 1.93 & 0.086 & 0.66 & 0.74 & 0.088 \\
Three factors** & 40 & $65.35^{* *}$ & 1.63 & 0.077 & 0.77 & 0.83 & 0.072 \\
Four factors** & 38 & 46.44 & 1.22 & 0.064 & 0.92 & 0.94 & 0.043 \\
Five factors*a $^{* a}$ & 35 & 38.33 & 1.10 & 0.057 & 0.97 & 0.98 & 0.028 \\
SEM $^{\mathrm{a}}$ & 65 & $96.16^{* *}$ & 1.48 & 0.062 & 0.87 & 0.93 & 0.063 \\
Correction $_{\text {Four factors** }}$ & 39 & 43.14 & 1.11 & 0.057 & 0.96 & 0.97 & 0.029 \\
SEM & 53 & $78.93 * *$ & 1.49 & 0.065 & 0.83 & 0.88 & 0.063 \\
\hline
\end{tabular}

SRMR standardized root mean residual, TLI Tucker-Lewis index, $C F I$ comparative fit index, RMSEA root-mean-square error of approximation

${ }^{*} p<0.05$ and $* * p<0.01$. For model $* p<0.05$ and $* *<0.01$ for improvement of fit compared to previous model based on change in Chi square

${ }^{\text {a } O r i g i n a l ~ r e s u l t s ~ s h o w e d ~ a ~ n o n-p o s i t i v e ~ d e f i n i t e ~ r e s i d u a l ~ m a t r i c ~}$
Table E2 Correcting Table 6

Mediation analysis of the relationship of gender and rating through experience and age variables $(N=122)$

\begin{tabular}{|c|c|c|}
\hline Path & $B[95 \% \mathrm{CI}]$ & $t$ score \\
\hline \multicolumn{3}{|l|}{ Direct paths } \\
\hline Gender to rating & $\begin{array}{l}-126.64[-224.52 \\
-28.78]\end{array}$ & $-2.56^{*}$ \\
\hline Games played to rating & $10.63[-25.53,46.78]$ & 0.58 \\
\hline $\begin{array}{l}\text { SCRABBLE specific } \\
\text { study alone to rating }\end{array}$ & $47.05[11.42,82.69]$ & $2.62 *$ \\
\hline $\begin{array}{l}\text { Other SCRABBLE to } \\
\text { rating }\end{array}$ & $-17.11[-32.96,-1.27]$ & $-2.14 *$ \\
\hline $\begin{array}{l}\text { SCRABBLE tournament } \\
\text { study to rating }\end{array}$ & $39.23[3.15,75.31]$ & $2.15^{*}$ \\
\hline Age to rating & $6.23[1.18,11.28]$ & $2.44 *$ \\
\hline Starting age to rating & $-3.88[-9.30,1.55]$ & -1.42 \\
\hline $\begin{array}{l}1 \text { st tournament age to } \\
\text { rating }\end{array}$ & $-11.89[-17.53,-6.26]$ & $-4.18 * *$ \\
\hline \multicolumn{3}{|l|}{ Indirect gender to rating } \\
\hline $\begin{array}{l}\text { Through games played to } \\
\text { rating }\end{array}$ & $-8.73[-24.81,48.08]$ & \\
\hline $\begin{array}{l}\text { Through SCRABBLE } \\
\text { specific study alone to } \\
\text { rating }\end{array}$ & $-24.52[-66.17,-3.62]$ & \\
\hline $\begin{array}{l}\text { Through other scrabble } \\
\text { to rating }\end{array}$ & $-13.49[-51.21,6.98]$ & \\
\hline $\begin{array}{l}\text { Through SCRABBLE } \\
\text { tournament study to } \\
\text { rating }\end{array}$ & $-14.75[-50.73,2.08]$ & \\
\hline Through age to rating & $68.35[18.02,157.95]$ & \\
\hline $\begin{array}{l}\text { Through starting age to } \\
\text { rating }\end{array}$ & $-4.83[-29.04,5.01]$ & \\
\hline $\begin{array}{l}\text { Through 1st tournament } \\
\text { age to rating }\end{array}$ & $-87.79[-174.46,-31.75]$ & \\
\hline
\end{tabular}

